\title{
PRODUÇÃO DE ESTATÍSTICAS E INOVAÇÃO TECNOLÓGICA PAEP 1996-2001
}

RoBerto Bernardes

\begin{abstract}
Resumo: Mapeamento da gênese e do ciclo evolutivo do debate metodológico e conceitual contemporâneo liderado pelas principais agências multilaterais e instituições internacionais produtoras de informações sobre inovação tecnológica à luz da experiência e do esforço de convergência metodológica da Fundação Seade na produção de pesquisas e novas métricas estatísticas que mensurem a criação e difusão do conhecimento na economia.

Palavras-chave: surveys de inovação; tecnologia; indicadores intersetoriais de produção do conhecimento.
\end{abstract}

Abstract: This article traces the genesis and evolutionary cycle of the contemporary methodological and conceptual debate being led by the principle multilateral international agencies and institutions that produce information on technological innovation, with concomitant consideration given to the methodological convergence practiced by Fundação Seade in the production of research and new statistical tools that measure the creation and dissemination of knowledge in the economy.

Key words: innovation surveys; technology; intersectorial indicators of the production of knowledge.

$\mathrm{O}$ propósito deste artigo é sistematizar o histórico institucional e a discussão contemporânea sobre produção, bem como a construção de séries intertemporais de estatísticas de inovação e difusão tecnológica no âmbito da OECD, da perspectiva de países em desenvolvimento, tendo como parâmetro a experiência da implementação da Paep - Pesquisa da Atividade Econômica Paulista, concebida pela Fundação Seade no Estado de São Paulo. O artigo está estruturado essencialmente em três partes. Na primeira, é operado um histórico da evolução das instituições produtoras de estatísticas, descrevendo o aperfeiçoamento dos conceitos e das metodologias de indicadores tecnológicos. A segunda parte é dedicada a relatar a experiência da Fundação Seade na implementação da Paep (aplicada no Estado de São Paulo) e da Paer Pesquisa da Atividade Econômica Regional, realizada em todas as Unidades Federativas do Brasil. As duas pesquisas de natureza econômica captaram informações sobre inovação e novas tecnologias na economia. Neste tópico, é registrada a metodologia aplicada, assim como os procedimentos de composição amostral e alguns resultados obtidos. Por fim, são retratados os prin- cipais aprendizados e desafios futuros para a produção de estatísticas de inovação e difusão tecnológica no Brasil.

\section{GÊNESE E EVOLUÇÃO DOS SURVEYS DE INOVAÇÃO TECNOLÓGICA NO PÓS-GUERRA}

Desde o pós-guerra, com o reconhecimento do progresso tecnológico como força motriz do crescimento econômico, as agências governamentais, organizações multilaterais e instituições produtoras de informações têm mobilizado grandes esforços no sentido de construir metodologias capazes em mensurar a nova dinâmica e a natureza da mudança tecnológica nas economias hegemônicas. Além da valorização das informações sobre CT\&I - Ciência, Tecnologia e Inovação para planejamento público e refinamento dos instrumentos de gestão para o desenvolvimento, tem se tornado candente o debate sobre a criação de novos indicadores que mensurem a produção do conhecimento, a participação das indústrias e dos serviços high-tech na economia e a alta correlação territorial dos processos de inovação e capacitação tecnológica das nações. As evidências sinalizam que as economias con- 
temporâneas são cada vez mais baseadas no conhecimento e no aprendizado proporcionado pela interação social. Com efeito, o regime de acumulação econômico tornouse mais interdependente das competências criadas pelo desenvolvimento científico e tecnológico e por seus sistemas nacionais de inovação. ${ }^{1}$

As pesquisas estatísticas sobre CT\&I nas economias cêntricas e em desenvolvimento inserem-se nesse contexto de crescente valorização conferida pelos respectivos governos e policy makers, que em estimulam, por meio de ações públicas, novos instrumentos e arranjos institucionais direcionados para a promoção do progresso da CT\&I, e pelo conhecimento das performances de suas economias. Na década de 50, surgiram as primeiras iniciativas para a mensuração dos inputs (insumos), basicamente investigando as variáveis relacionadas às atividades de P\&D - Pesquisa e Desenvolvimento, entendidas como uma proxy dos esforços de inovação tecnológica. Esta agenda de pesquisa era orientada pela noção de um "movimento linear no processo de inovação", compreendido como produto de um modelo lógico seqüencial expresso nas fases: invenção-inovação-difusão. A referência teórica do processo de inovação sustentava-se no modelo linear, cuja cadeia seqüencial de atividades seria a pesquisa básica, pesquisa aplicada, desenvolvimento experimental, produção, mercado e marketing. De acordo com as preposições de Kline e Rosemberg (1986), a inovação ocorreria a partir de uma seqüência linear de causas e efeitos, na qual o desenvolvimento da pesquisa básica desencadeia outras etapas para geração da inovação. Nesse modelo, essas etapas são distintas e isoladas, pressupondo uma divisão institucional e uma separação entre os atores institucionais. Esse modelo, que vigorou como compreensão do processo de inovação nas décadas de 50 e 60 , influenciou instituições na definição de políticas públicas e corporativas de P\&D.

Em 1963, a OECD - Organização para Cooperação do Desenvolvimento Econômico, editou o Manual Frascati ${ }^{2}$ escrito por experts da comunidade européia e da divisão de análise econômica e estatísticas desta organização, dando origem a uma família de manuais metodológicos para mensurar as atividades de inovação tecnológica, com o objetivo de sistematizar e harmonizar a construção de séries estatísticas intertemporais e internacionalmente comparativas. Os surveys de inovação acompanharam o ciclo evolutivo das transformações econômicas, tecnológicas e sociais, alterando-se ao longo do tempo seus conceitos, metodologias e instrumentos de captação des- tes fenômenos, mas seguindo as recomendações de preservação da comparabilidade internacional destas informações. Nesse aspecto, os manuais metodológicos foram as principais referências para a harmonização destas pesquisas (Quadro 1). Os surveys pioneiros realizados na década de 60 para elaboração de indicadores de C\&T (ciência e tecnologia) tinham como referência o Manual Frascati e objetivavam, a partir de pesquisas estatísticas, a construção de indicadores de intensidade de P\&D (número de pessoas alocadas e gastos), privilegiando ainda informações sobre o desenvolvimento experimental, entre outros. Adquire "status paradigmático", neste período, a experiência da National Science Foundation, ${ }^{3}$ localizada nos EUA, que se consolidou como a instituição de pesquisa pioneira na produção de indicadores sobre gastos e pessoal alocado em atividades de P\&D.

Nas décadas de 70 e 80 , foram introduzidos os indicadores de balanço de pagamentos tecnológico ${ }^{4}$ - os indicadores de output (resultados) -, como os de produções científica (bibliometria) e tecnológica (patente). Os indicadores bibliométricos são as informações sobre os artigos publicados nas revistas indexadas pelo Institute for Scientific Information - ISI, com sede nos Estados Unidos. ${ }^{5}$ As patentes formam até hoje o principal indicador de produção tecnológica nos países centrais e o número delas é uma medida que auxilia a avaliação da capacidade de inovação. Entre as atividades patentárias, ${ }^{6}$ a modalidade mais relevante para indicar o surgimento de novas tecnologias é aquela concedida para o privilégio de invenção (propriedade intelectual). ${ }^{7}$ Com o objetivo de mensurar a participação das atividades baseadas em conhecimento na geração de riqueza nos países industrializados desenvolveu-se neste período a primeira proposta da $\mathrm{OECD}^{8}$ para a classificação de produtos industriais segundo uma taxonomia setorial privilegiando a intensidade tecnológica.

No final da década de 80 e mais particularmente na de 90, a partir da ação conjuntas das agências produtoras de estatísticas internacionais inicia-se uma nova etapa das pesquisas estatísticas de inovação com a revisão da metodologia, incorporando e ampliando os conceitos, não restringindo-os exclusivamente às atividades de $\mathrm{P} \& \mathrm{D}$. A percepção de que o processo de inovação e aprendizado tecnológico é resultado de uma pletora complexa de interações (learning by interaction) entre os diversos atores institucionais, empresas, fornecedores, usuários e agências de fomentos que integram o sistema de CT\&I e, por isso, implicando em trajetórias tecnológicas sistêmicas e não-lineares, exigiu o aperfeiçoamento da metodologia e em novos indicadores que 
QUADRO 1

Documentos Metodológicos de Mensuração para Construção de Indicadores de CT\&I

\begin{tabular}{|c|c|}
\hline Ano & Documento \\
\hline 1963 & Manual Frascati \\
\hline 1978 & Unesco. Recommendation concerning the International Standardization of Statistics on Science and Technology, Paris, 27 November \\
\hline 1984 & Unesco. Manual for statistics on scientific and technological activities (Unesco Division of Statistics on Science and Technology, Office of Statistics ST-84/WS/12) \\
\hline 1992 & TEP - The Technology-Economy-Productivity Program - The Key Relationships \\
\hline 1994 & Using Patent Data as Science and Technology Indicators - Patent Manual \\
\hline 1994 & Manual de Oslo (5⿳亠丷厂 edição) \\
\hline 1994 & Manual de Canberra \\
\hline 1995 & The Measurement of Scientific and Technological Activities Manual on the Measurement of Human Resources Devoted to S\&T "Canberra Manual" \\
\hline 1997 & Manual de Oslo (2ª Versão). Proposed Guidelines for Collecting and Interpreting Technological Innovation \\
\hline 1997 & Revision of the high-technology sector and product classification \\
\hline 1997 & Committee for information, computer and comunication policy: measuring eletronic commerce, Paris, OECD/GD(97)185. \\
\hline 1998 & Mesuring intangible investiment. Intangible investiment in the statistical frameworks for the collection and comparison of science and technology statistics. \\
\hline 2000 & $\begin{array}{l}\text { Stuz, J. "Las encuestas de innovación latinoamericana: un análisis comparativo de las formas de indagación”. Trabajo preparado para el Proyecto } \\
\text { Normalización de Indicadores de Innovación Tecnológica en América Latina, OEA, Junio. }\end{array}$ \\
\hline 2000 & $\begin{array}{l}\text { Manual de Bogotá - Normalización de Indicadores de Innovación Tecnológica en América Latina y el Caribe - OEA Organización de Estados Americanos - } \\
\text { Ricyt, Colciencias, Cyted, OcyT. }\end{array}$ \\
\hline 2000 & $\begin{array}{l}\text { Brisolla, S. y Quadros, R. Innovaciones en los indicadores de innovación. Un estudio de las metodologías adoptadas en los países en vías de desarollo. Trabajo } \\
\text { preparado para el Proyecto Normalización de Indicadores de Innovación Tecnológica en América Latina. OEA, Junio. }\end{array}$ \\
\hline
\end{tabular}

dimensionassem estes novos fenômenos relacionados às economias de aprendizado (Lundvall, 1992). Esta nova agenda de pesquisas passou a interpretar a inovação não mais como um resultado absoluto e restrito às rotinas de $\mathrm{P} \& \mathrm{D}$, mas como um fenômeno oriundo dos processos de aprendizagem e, por isso, dependente de outras esferas produtivas e institucionais. Assim, tornaram-se imperativas a elaboração e a captação de indicadores de difusão de novos equipamentos, de recursos humanos, ${ }^{9}$ do uso de novas tecnologias de informação e comunicação, da adoção e adaptação de novos processos e das formas de interação entre as empresas, usuários e instituições de CT\&I.

A noção de que os processos de capacitação e difusão tecnológica na economia constituem fundamentos para o desenvolvimento econômico e social implicou a criação de dois novos indicadores: o TAI - Technology Achievement Index e, mais recentemente, o ArCo - Capacitação Tecnológica para o Desenvolvimento. Ambos visam construir indicadores de inovação e capacitação tecnológica para países desenvolvidos e em desenvolvimento a partir de algumas dimensões: criação, difusão e adoção de novas tecnologias; difusão das tecnologias existentes, que constituem base para a introdução de novas; idade das redes de TIs; construção da habilidade dos recursos humanos para a geração e uso de tecnologia; e infra-estrutura tecnológica. ${ }^{10}$
Com o consenso entre os especialistas que o setor de serviços representa cada vez mais um elo crítico no processo de integração econômica setorial, principalmente pela função de geração de emprego e renda, assim como pelo crescente peso destas atividades tecnológicas na sua interface com a indústria para o fomento do progresso e a criação da riqueza social nas economias industriais avançadas, iniciaram-se esforços por parte das agências produtoras de estatísticas na implementação de surveys de inovação neste segmento (Quadro 2).

\section{SURVEYS DE INOVAÇÃO: TIPOS DE ABORDAGEM}

A aplicação dos surveys ou da construção dos indicadores de inovação pode ser elaborada a partir de duas abordagens de mensuração: o objeto econômico, no caso do resultado ou produto da inovação; e o sujeito econômico, no caso da inovação na empresa.

\section{A Abordagem Baseada no Objeto}

A construção de indicadores a partir da abordagem baseada no objeto tem como base a mensuração por meio da contagem e a análise dos resultados da inovação. A 
QUADRO 2

Evolução dos Indicadores de Ciência, Tecnologia e Inovação no Pós-Guerra

\begin{tabular}{|c|c|c|c|c|}
\hline Indicadores & Décadas de 50 e 60 & Década de 70 & Década de 80 & Década de 90 \\
\hline $\begin{array}{l}\text { Principais indicadores } \\
\text { utilizados }\end{array}$ & P\&D & $\begin{array}{l}\text { P\&D } \\
\text { Patentes } \\
\text { Balanços de } \\
\text { pagamentos } \\
\text { tecnológicos }\end{array}$ & $\begin{array}{l}\text { P\&D } \\
\text { Patentes } \\
\text { Balanços de pagamentos tecnológicos } \\
\text { Classificação de produtos por intensidade } \\
\text { e conteúdo tecnológico } \\
\text { Bibliométricos } \\
\text { Recursos humanos } \\
\text { Surveys de inovação na indústria }\end{array}$ & $\begin{array}{l}\text { P\&D } \\
\text { Patentes } \\
\text { Balanços de pagamentos tecnológicos } \\
\text { Classificação de produtos por intensidade } \\
\text { conteúdo tecnológico } \\
\text { Bibliométricos } \\
\text { Recursos humanos (ocupações científicas) } \\
\text { Surveys de inovação nos serviços } \\
\text { Inovações citadas na literatura científicas } \\
\text { Surveys de tecnologias de produção } \\
\text { Suporte público para tecnologias industriais } \\
\text { Investimentos intangíveis } \\
\text { Indicadores de tecnologias de informação e } \\
\text { comunicação (TCls) } \\
\text { Matriz de insumo-produto } \\
\text { Capital de risco (venture capital) } \\
\text { Fusões e aquisições, joint venture, alianças } \\
\text { estratégicas } \\
\text { Produtividade }\end{array}$ \\
\hline $\begin{array}{l}\text { Conceito e padrão } \\
\text { de inovação }\end{array}$ & LINEAR & & $>$ INTEGRADO EM CADEIA & $>$ SISTÊMICO \\
\hline $\begin{array}{l}\text { Função dos experts e } \\
\text { instituições produtoras } \\
\text { de estatísticas na área } \\
\text { de indicadores de CT\&I }\end{array}$ & \multicolumn{3}{|c|}{ Fornecedores de metodologias e dados } & $\begin{array}{l}\text { Fornecedores de dados, metodologias, } \\
\text { análises; integração de vários tipos de } \\
\text { indicadores, análise conjunta e complementar } \\
\text { com indicadores socioeconômicos }\end{array}$ \\
\hline
\end{tabular}

Fonte: Archibugi; Sirilli (2000).

maior parte dos surveys realizados foi ocasional e, por isso, apresentando algumas desvantagens para exercícios de comparações internacionais. Neste grupo incluem-se as estatísticas de P\&D, as informações sobre patentes, indicadores bibliométricos, informações sobre os fluxos comerciais de produtos de alta tecnologia, balanço de pagamento tecnológico e indicadores de recursos humanos de alta qualificação. A principal crítica a este tipo de abordagem reside no argumento de que a captação destas informações limita-se apenas às inovações bem sucedidas, não comparando as empresas inovadoras e as não-inovadoras (Archibugi; Sirilli, 2000:09).

\section{A Abordagem Baseada no Sujeito}

O foco da abordagem baseada no sujeito é basicamente a empresa (o sujeito). Os instrumentos de coleta são estruturados com a finalidade de investigar questões quantitativas e qualitativas sobre as atividades de inovação, abrangendo as empresas inovadoras e as não-inovadoras. Desde 1970, estes surveys apresentavam uma periodicidade ocasional e irregular e as iniciativas eram financiadas por instituições acadêmicas de pesquisa. Somente na década de 80, a partir das iniciativas da OECD, é que foram estabelecidos três vetores de organização para a consecução permanente deste surveys: periodicidade regular; padronização da metodologia estatística; e padronização dos questionários.

Nos anos 90, a implementação de pesquisas de inovação com este tipo de abordagem tem prevalecido em larga escala na Europa e nos países não-europeus, após a publicação do Manual de Oslo e a aplicação dos três Community Innovation Surveys (CIS). Alguns dos fatores que favoreceram a consecução dos CISs e deste tipo de abordagem são à alta potencialidade de comparação internacional das estatísticas, a organização de séries temporais e uma investigação mais ampla e representativa dos processos de surgimento da inovação e do aprendizado tecnológico. 


\section{MANUAL DE OSLO: CONCEITOS E MEDIDAS}

As iniciativas para mensurar a natureza da mudança tecnológica conduziram ao longo dos anos 80 , ao desenvolvimento de pesquisas baseadas no tipo de abordagem que privilegia os sujeitos (as empresas), buscando identificar qualitativa e quantitativamente suas atividades tecnológicas. Em particular, os surveys de inovação, como são denominadas estas pesquisas, cuja metodologia de coleta e análise está sistematizada no Manual de Oslo, ${ }^{11}$ investigam os setores industrial e de serviços.

É neste contexto que foi desenvolvido pela OECD, em conjunto com a Eurostat (Comunidade Européia) e DGXIII do European Innovations Monitoring System, o Manual de Oslo em 1992 (revisado posteriormente em 1996), com o objetivo de harmonizar a coleta e as análises de surveys de inovação na Europa, com base no principal sujeito do processo inovativo: as empresas. Com o apoio da Eurostat (Statistical Office of the European Communities), foram revisados os conceitos de inovação tecnológica e sua metodologia de mensuração. As revisões do Manual de Oslo foram operadas, sobretudo, após a avaliação das experiências de implementação dos surveys na Europa, em 1993 (CIS-I), 1998 (CIS-II) e 2001 (CISIII) (Costa, 2003:77). Na revisão de 1996, não foram feitas mudanças significativas, mas forte ênfase foi conferida à orientação dos procedimentos de coleta das informações relevantes para a promoção de políticas e para as características do estudo da inovação. Definiu-se mais precisamente a distinção entre as inovações tecnológicas e aquelas puramente estéticas e organizacionais, identificando com maior rigor a origem, o principal agente da inovação e o nível de originalidade da inovação para o mercado. A maior novidade consistiu na inclusão do setor de serviços nos surveys de inovação.

A primeira pesquisa de inovação baseada no Manual de Oslo foi o Community Innovation Survey - CIS-I, realizado em 1993 (para o período-base 1992-93). Neste primeiro levantamento, foram incluídas aproximadamente 40.000 empresas de 13 países europeus: Bélgica, Alemanha, Dinamarca, França, Grécia, Itália, Irlanda, Luxemburgo, Holanda, Portugal, Espanha, Reino Unido e Noruega (Archibugi; Sirilli, 2000).

Apesar dos esforços realizados no CIS-I, permaneceram as dificuldades de harmonização entre os países. $\mathrm{O}$ Manual de Oslo foi então revisado em 1996 e adotado como base metodológica para um segundo Community Innovation Survey - o CIS-II. O CIS-II foi conduzido em
1998, para o período 1994-96, sendo respondido por aproximadamente 55.000 empresas dos setores manufatureiros e de serviços de 15 países europeus: Áustria, Bélgica, Alemanha, Dinamarca, Finlândia, Suécia, França, Itália, Irlanda, Luxemburgo, Holanda, Portugal, Espanha, Reino Unido e Noruega. Além de alterações na elaboração do questionário, este segundo survey de inovação na Europa incluiu o setor de serviços. A metodologia propugnada pelo programa CIS se entendeu por outros países da Europa Central e do Leste, da América Latina (entre outros, o Brasil), Canadá, Austrália, Coréia do Norte, México, Suíça e Turquia. Em 2002, foi iniciado o terceiro Community Innovation Survey - CIS-III, coletando dados para o período 1998-2000 (Costa, 2003:78).

Segundo o Manual de Oslo, o conceito de inovação tecnológica corresponde à introdução no mercado de um produto (bem ou serviço) novo ou significativamente melhorado, ou à introdução, por parte da empresa, de processos novos ou significativamente melhorados. A inovação pode ser baseada em novos desenvolvimentos tecnológicos, em novas combinações de tecnologias existentes, ou na utilização de outro tipo de conhecimento adquirido pela empresa. A metodologia faz uma distinção entre inovação de produto e de processo. A inovação de produto corresponde à introdução no mercado de um produto (bem ou serviço) novo ou significativamente melhorado relativamente às suas características fundamentais, às suas especificações técnicas, ao software ou outros componentes imateriais incorporados, às utilizações para que foi concebido, ou à facilidade de utilização. A inovação tem que ser nova para a empresa; não tem que ser necessariamente nova no mercado servido pela empresa. A inovação pode ter sido desenvolvida tanto pela empresa como fora dela.

A inovação de processo corresponde à adoção de métodos de produção novos ou significativamente melhorados, assim como de meios novos ou significativamente melhorados de fornecimento de serviços e de distribuição de produtos. O resultado da inovação de processo terá que ter um impacto significativo na produção, na qualidade dos produtos (bens ou serviços) ou nos custos de produção e de distribuição. A inovação tem que ser nova para a empresa; não tem que ser necessariamente nova no mercado servido pela empresa. O Manual sugere um conjunto de exemplos de inovação tecnológica, a saber:

- inovação de produto: módulos para a área da ciência da vida produzidos através de engenharia biológica; programa de estabilização eletrônica para veículos a motor 
$(E S P)$; linhas de alta tensão isoladas com gás; digitalização de processos de impressão; novos tipos de sistemas de lâminas para produção de aparas de madeira (wood chips); novo modelo de unidade de remoção e recuperação de água; medição de partículas por sensores em exaustão de gases; novo tipo de papel para impressoras específicas; novos tipos de motores em navios, e linhas de alta tensão isoladas com gás;

- inovação de processo: novos sistemas de CAD; novos sistemas de distribuição da informação; interligação de sistemas de processamento de dados, software para computadores em rede; introdução de métodos de assistência/ auxílio e/ou baseados em computador para desenvolvimento de produto; introdução de programas de simulação com base em elementos finitos para otimização de componentes; recurso ao comércio eletrônico interligado com a produção (ex. bancos eletrônicos com ofertas personalizadas, compras via Internet); disponibilização de canais diretos de comunicação entre o cliente e o produtor; controle do tempo e fase de execução da produção pela Internet, entre outros;

- exemplos de não inovações tecnológicas: melhorias em produtos com o propósito de torná-los mais atrativos aos consumidores sem mudança em suas características tecnológicas, como as inovações estéticas ou de estilo (como mudança de cor, alterações superficiais, um novo corte de tecido, etc.), muito comuns nas indústrias têxteis ou de vestuário e calçados, entre outras - nestes segmentos, deve ser considerada inovação tecnológica a aplicação ou desenvolvimento de um novo tecido (fibra), que implique pesquisa e desenvolvimento de um novo material -; pequenas mudanças tecnológicas (melhorias não substanciais) de produtos e processos, modificações que não apresentam grande novidade, mudanças puramente organizacionais; modificações de produtos e processos cuja novidade não diz respeito às características objetivas de uso ou desempenho dos produtos, ou da maneira pela qual eles são produzidos ou distribuídos, mas antes às suas qualidades estéticas ou subjetivas. A implementação das normas ISO 9000 só deve ser considerada uma inovação tecnológica se a sua introdução implicou o desenvolvimento de uma nova tecnologia ou gerou um avanço tecnológico significativo em produto ou processo $^{12}$ (Quadro 4).

De acordo com o conceito propugnado pelo Manual de Oslo, o indicador de desempenho inovador das empresas ou de um determinado setor é sua taxa de inovação, medida como a participação percentual das empresas inovadoras, seja em número de empresas seja em valor, naquele setor. Portanto, a taxa de inovação, em períodos selecionados, mensura a participação das empresas que introduziram produtos e/ou processos tecnológicos novos ou substancialmente modificados, no total das empresas.

\section{PRODUÇÃO DE INDICADORES ESTATÍSTICOS DE INOVAÇÃO EM PAÍSES EM DESENVOLVIMENTO}

$\mathrm{Na}$ América Latina e na Central, em particular no Brasil, a elaboração de metodologias e a construção de séries históricas de indicadores a partir da aplicação de surveys de inovação eram ações institucionais pouco exploradas nas pesquisas estatísticas até a década de 90. Como observou Quadros et al. (2003:3), "desde os trabalhos pioneiros de Erber, Dahlman e Katz (1987), até estudos bem recentes, como os de Figueiredo (2001), os estudos de caso e setoriais têm sido decisivos para apontar a natureza incremental, cumulativa e variada em escopo, da capacitação tecnológica das empresas industriais. No entanto, esses estudos se referem a um número limitado de setores e não permitem generalizações".

A partir da segunda metade dos anos 90, registram-se algumas iniciativas importantes na América Latina, no campo dos surveys de inovação no setor industrial, tratando-se em sua maioria de pesquisas focadas nas abordagens baseadas no sujeito, mas nem sempre adotando o Manual de Oslo como referencial metodológico básico. Entretanto, a ampla cobertura amostral proporcionada por estas pesquisas permitiu a elaboração de exercícios de comparação dos resultados. São exemplos as pesquisas do México (1997), Colômbia (1996), Venezuela (1997), Argentina (1997) e Chile (1995). Deste conjunto de pesquisas implementadas, nos casos de México, Colômbia e Chile, foram seguidas as recomendações do Manual de Oslo, enquanto as da Venezuela, Uruguai e Argentina investigaram aspectos sobre a capacidade tecnológica e inovadora das empresas e a do Uruguai partiu de um escopo mais abrangente, investigando, além destas variáveis, elementos sobre os recursos humanos na indústria manufatureira (Stuz, 1999).

A adoção do Manual de Oslo em surveys de inovação em países em desenvolvimento tem suscitado um conjunto de indagações quanto à aderência de metodologias desenvolvidas em economias avançadas e aplicadas em países em desenvolvimento que apresentam um padrão 
QUADRO 3

Formas de Abordagens dos Surveys de Inovação

\begin{tabular}{|c|c|c|}
\hline Características da Abordagem & Abordagem Baseada no Objeto & Abordagem Baseada no Sujeito \\
\hline Unidade de análise & Inovação tecnológica & Empresa \\
\hline Método de coleta da informação & $\begin{array}{l}\text { Coleta de informações realizada de diferentes fontes } \\
\text { produtoras públicas e privadas, surveys especializados } \\
\text { e detalhados. São exemplos as informações sobre } \\
\text { patentes, P\&D, bibliometria, etc. }\end{array}$ & $\begin{array}{l}\text { Coleta de informações no âmbito da empresa pela } \\
\text { aplicação de questionários ou entrevistas diretas. }\end{array}$ \\
\hline Forma de captação da inovação & $\begin{array}{l}\text { Registro de informações sobre o resultado (output) do } \\
\text { processo de inovação }\end{array}$ & $\begin{array}{l}\text { Registro de informações sobre os insumos (input) do } \\
\text { processo de inovação. }\end{array}$ \\
\hline Periodicidade & Surveys ocasionais & $\begin{array}{l}\text { Surveys periódicos e intertemporais para a construção } \\
\text { de séries estatísticas através do programa CIS } \\
\text { (Community Innovation Survey) }\end{array}$ \\
\hline Cobertura & Amostra de inovações bem-sucedidas & $\begin{array}{l}\text { Amostra de inovações bem e mal-sucedidas. } \\
\text { Empresas inovadoras e não-inovadoras, abrangendo } \\
\text { os setores da indústria e dos serviços }\end{array}$ \\
\hline Critérios de classificação & $\begin{array}{l}\text { Área tecnológica } \\
\text { Produto } \\
\text { Atividade econômica principal da empresa }\end{array}$ & $\begin{array}{l}\text { Tamanho da empresa } \\
\text { Tipos de inovação } \\
\text { Formas de cooperação e interação } \\
\text { Atividade econômica principal da empresa }\end{array}$ \\
\hline Exemplos típicos & $\begin{array}{l}\text { Small bussiness administration, EUA } \\
\text { (Acs \& Audretsch, 1991) }\end{array}$ & $\begin{array}{l}\text { Surveys de inovação } \\
\text { (CIS - Communitty Innovation Surveys) } \\
\text { (Guellec and Pattinson, 2002) }\end{array}$ \\
\hline
\end{tabular}

Fonte: Archibugi; Sirilli (2000).

QUADRO 4

Tipo e Grau da Novidade e Definição da Inovação

\begin{tabular}{|c|c|c|c|c|c|c|}
\hline & & & \multicolumn{3}{|c|}{ Inovação } & \multirow{3}{*}{$\begin{array}{c}\text { Não- } \\
\text { Inovação }\end{array}$} \\
\hline & & & Maximum & Intermediária & Minimum & \\
\hline & & & $\begin{array}{c}\text { Nova para } \\
\text { o Mundo }\end{array}$ & (1) & $\begin{array}{c}\text { Nova para } \\
\text { Empresa }\end{array}$ & \\
\hline \multirow{6}{*}{$\begin{array}{l}\text { Inovação } \\
\text { Tecnológica de } \\
\text { Produto e } \\
\text { Processo } \\
\text { (ITPP) }\end{array}$} & \multirow{3}{*}{$\begin{array}{l}\text { Tecnologica- } \\
\text { mente nova }\end{array}$} & Produto & & & & \\
\hline & & Processo de produção & & & & \\
\hline & & Processo de distribuição & & & & \\
\hline & \multirow{3}{*}{$\begin{array}{l}\text { Melhoria } \\
\text { tecnológica } \\
\text { significativa }\end{array}$} & Produto & & & & \\
\hline & & Processo de produção & & & & \\
\hline & & Processo de distribuição & & & & \\
\hline Outra inovação & & Puramente organizacional & & & & \\
\hline \multirow{4}{*}{ Não-Inovação } & \multirow{4}{*}{$\begin{array}{l}\text { Mudança não } \\
\text { significativa } \\
\text { Mudança sem } \\
\text { novidade ou } \\
\text { outro } \\
\text { melhoramento } \\
\text { criativo }\end{array}$} & Produto & & & & \\
\hline & & Processo de produção & & & & \\
\hline & & Processo de distribuição & & & & \\
\hline & & Puramente organizacional & & & & \\
\hline & ITPP & Outro tipo de inov & & Não-inova & & \\
\hline
\end{tabular}

Fonte: Manual de Oslo.

(1) Pode ser geograficamente nova para o país ou região. 
diferenciado da mudança tecnológica. Na ótica destas indagações, a Ricyt - Red Iberoamericana/Interamericana de Indicadores de Ciencia e Tecnología desenvolveu o Manual de Bogotá (Jaramillo et al., 2000), resultado de um esforço conjunto de pesquisadores latino-americanos para contornar dificuldades da adoção do Manual de Oslo em pesquisas de inovação na América Latina. Como observou Costa (2003:89), apesar dos esforços, muitas das críticas ao Manual de Oslo não foram superadas pelo Manual de Bogotá, que acabou por não alcançar uma unanimidade entre os especialistas enquanto status referencial de um manual metodológico de inovação para a América Latina. ${ }^{13}$

No Brasil, a literatura econômica acumulou considerável estoque de conhecimento empírico, baseado em estudos setoriais e em estudos de caso de empresas, ${ }^{14}$ mas eram poucas as iniciativas de estudos analíticos para a compreensão da natureza da inovação, difusão tecnológica e de seus impactos, sob uma perspectiva transversal e intersetorial na economia. A Anpei - Associação Nacional de Desenvolvimento das Empresas Industriais desenvolveu no Brasil, a partir de 1992, uma pesquisa pioneira inspirada na experiência da National Science Foundation, uma base de indicadores empresariais de P\&D. Constituída a partir de um painel de cerca de 365 empresas, esta base reúne informações sobre $P \& D$ e engenharia não rotineira. A pesquisa, desde o início, contou com o apoio do governo federal através do Pacti - Programa de Apoio à Capacitação Tecnológica da Indústria e de agências, como Finep e Sebrae. Saliente-se que o inquérito da Anpei não se enquadra nos padrões dos surveys de inovação da OECD, sendo uma pesquisa focada na P\&D das empresas. ${ }^{15}$

\section{PAEP/SEADE: CONVERGÊNCIA E INOVAÇÃO NA PRODUÇÃO DE ESTATÍSTICAS}

Diante da complexidade da nova agenda de pesquisas estatísticas, a Fundação Seade dedicou-se, desde 1992, à arquitetura de uma nova metodologia, buscando captar os novos processos econômicos e inovativos, parcialmente eclipsados pela ausência de informações, no Estado de São Paulo. O objetivo de iluminar e mensurar o real dimensionamento dos impactos derivados das transformações macroeconômicas sobre a estrutura produtiva paulista em particular, somado à inexistência de dados atualizados, motivou a elaboração da Pesquisa da Atividade Econômica Paulista - Paep.
Recorde-se que, desde 1960, a produção de estatísticas econômicas no Brasil esteve fortemente ancorada na realização dos censos econômicos pelo IBGE, com periodicidade qüinqüenal a partir de 1970 até 1985, quando foram suspensos. Saliente-se que a disposição do IBGE em não mais implementar censos econômicos deveu-se não somente à crise do sistema estatístico nacional (SEN), mas também a uma decisão estratégica como forma de modernização e redução dos custos de monitoramento da economia, aliada à política de descentralização em curso naquele órgão desde a missão Canadá (1994/95). ${ }^{16}$ Naquele momento eram poucas as iniciativas estaduais ou municipais na produção de informações econômicas e tecnológicas, mesmo nas localidades que eram providas de instituições públicas de produção de estatísticas. As incertezas geradas pelo protelamento do Censo Demográfico de 1990 para 1991, a não realização do Censo Econômico de 1990, o atraso na divulgação das pesquisas anuais (PIA - Pesquisa Industrial Anual, PAC - Pesquisa Anual do Comércio, etc.) e as dificuldades de acesso aos resultados do Censo Econômico são alguns dos exemplos deste período. Simultaneamente, entrava em ebulição o interesse no cenário nacional conferido aos movimentos empresariais de reestruturação, difusão tecnológica e na emergência das cidades e dos espaços territoriais enquanto locus privilegiados para a compreensão dos processos de inovação e aprendizado e, por isso, reacendia-se o debate sobre a necessidade de mensuração dos novos indicadores de conhecimento na economia e nas diferentes regiões do Estado. Os novos indicadores seriam estratégicos para a análise da economia paulista e para a definição de políticas públicas de desenvolvimento regional. ${ }^{17}$

Em sintonia com a nova agenda de pesquisas contemporâneas, a Fundação Seade acumulou ao longo destes anos uma significativa experiência na concepção e gestão de pesquisas de inovação tecnológica, tendo como parâmetros a experiência internacional de produção de estatísticas. Nesse sentido, a aplicação da Paep consagrou-se como uma pesquisa econômica estrutural que incorporava em seu projeto o primeiro survey de inovação realizado no Brasil, ${ }^{18}$ adotando o referencial conceitual recomendado pelo Manual de Oslo e tendo como universo de investigação as empresas industriais do Estado de São Paulo. Além deste survey, foram incluídos no questionário da Paep três capítulos destinados aos estilos de gestão da produção, à automação industrial e à difusão de novas tecnologias de informação e comunicações, permitindo avaliar a magni- 
tude e amplitude da base tecnológica e informacional das empresas industriais.

De forma geral, os indicadores setoriais de inovação tecnologia da Paep foram construídos a partir de cinco perspectivas:

- esforço de inovação, captado para a indústria e os serviços, medido através de um conjunto de informações tendo como base duas variáveis constantes no questionário, referentes especificamente a essa temática: algum tipo de inovação tecnológica na empresa, seja de produto, seja de processo; e se a empresa, nesse período, desenvolveu atividades de pesquisa e desenvolvimento (P\&D);

- difusão de novas tecnologias, medida por meio de um conjunto de variáveis intersetoriais que investigavam a amplitude da utilização de equipamentos de automação, da utilização de técnicas de controle de qualidade e produtividade e da utilização de computadores: uso de técnicas de produtividade e qualidade (just-in-time, engenharia simultânea, uso de minifábricas, etc.); uso de equipamentos de automação com base microeletrônica; uso de sistemas CAD/CAE/CAM (tecnologias utilizadas na engenharia de projeto); uso de equipamentos de automação de processos; uso de computadores; uso de redes de informação corporativa aplicadas à engenharia de projeto e produção; entre outras;

- uso da tecnologia, entendido como estilos de gestão, complementar ao processo de difusão da inovação tecnológica. As variáveis escolhidas para esta caracterização são: se os computadores das empresas estavam ligados em rede, configurando um sistema de troca de dados interno; uso de sistemas de troca e consulta eletrônica de dados externa (rede de longa distância, e-commerce, ${ }^{19}$ EDI, Internet, etc.); informações quantitativas e de perfil do uso de computadores, entre outros;

- origem e fontes das novas tecnologias: nacionalidade do capital controlador; origem do agente que desenvolveu a inovação; nacionalidade do agente que realizou acordos de cooperação para o desenvolvimento da inovação; fontes de informação para as atividades de inovação tecnológica; entre outras;

- impactos da tecnologia: participação na receita dos novos produtos; informações sobre patentes, indicadores de produtividade; entre outras.

\section{A Experiência do Survey de Inovação na Paep}

A Paep foi uma iniciativa pioneira no cenário de produção estatística nacional, na qual pesquisou-se um uni- verso representativo de mais de 40.000 empresas industriais no Estado de São Paulo, incluindo no questionário deste setor um capítulo composto por nove questões dedicadas às atividades inovadoras e rotinas de $\mathrm{P} \& \mathrm{D}$ destas empresas. A metodologia utilizada para o survey de inovação na Paep foi a mesma recomendada pelo Manual de Oslo, tendo como parâmetro o questionário da CIS-I Community Innovation Survey, assegurando assim a comparabilidade dos indicadores com outros surveys de inovação. As questões mais semelhantes ao CIS-I referiamse a:

- adoção ou não de, pelo menos, uma inovação tecnológica pela empresa, de produto e/ou de processo;

- classificação da importância dos motivos da adoção de inovações;

- classificação da importância das fontes de informação utilizadas pela empresa para a inovação;

- indicação pela empresa do percentual das vendas decorrente de novos produtos;

- dispêndios e número de funcionários empregados em atividades de $\mathrm{P} \& \mathrm{D}$, com a discriminação do subconjunto de empregados em P\&D com curso universitário completo.

A Paep combinou a investigação de variáveis econômicas comuns em pesquisas estruturais com a abordagem de variáveis quantitativas e qualitativas relacionadas à difusão tecnológica. A definição das variáveis de difusão tecnológica foi diferenciada de acordo com o setor de atividade econômica.

As informações foram coletadas em 1997, tendo 1996 como ano-base para a atividade econômica, e o período 1994-1996, para as questões que se referiam a intervalos de tempo para inovação. A Paep investigou uma amostra estratificada de empresas, identificadas e selecionadas com base nas informações contidas no cadastro. Para a constituição da amostra, as empresas da população de referência (empresas do cadastro) foram divididas em dois estratos: certo e aleatório. O primeiro abrange as empresas classificadas como industriais, com 30 ou mais empregados e que, em 1995, possuíssem sua sede, ou ao menos uma unidade produtiva, em operação e 30 ou mais pessoas ocupadas no Estado de São Paulo. O estrato aleatório compreendeu somente empresas de pequeno porte (entre 5 e 29 empregados), que possuíam sede no Estado São Paulo. Com base nestes critérios, selecionou-se uma amostra inicial de 19.334 empresas industriais, sendo 12.476 do estrato certo e 6.858 do estrato aleatório. A amostra final (efetiva) da Paep totalizou 10.658 empresas indus- 
triais e, expandida, correspondeu ao universo de 41.466 empresas.

Fizeram parte da Paep/96 todas as empresas dos segmentos da indústria de transformação, da extrativa, da construção civil, de serviços de informática, bancos e comércio. A construção civil foi incluída, após estudos realizados junto a entidades de classe, devido à importância que este segmento tem como absorvedor de mão-de-obra e por estar sendo alvo de processos de reestruturação técnico-produtiva. Tendo em vista a integração com o Sistema de Estatísticas Nacional (SEN), buscou-se maximizar a comparabilidade entre a Paep e as pesquisas econômicas produzidas por outras fontes. Para assegurar maior homogeneidade entre os vários segmentos estudados, adotou-se o sistema da CNAE/95 - Classificação Nacional de Atividades Econômicas, com a disponibilização das informações do Cadastro do IBGE de 1996. Complementarmente, para o detalhamento da análise de alguns segmentos mais relevantes do ponto de vista econômico e dos processos de reestruturação produtiva do Estado de São Paulo, estabeleceu-se uma agregação especial, denominada Caepaep - Classificação de Atividade Econômica específica da Paep, que orientou a amostragem da pesquisa. A base de informações da Paep, devido à sua ampla cobertura e representatividade estatística, permitiu que se explorasse a influência das características econômicas das empresas sobre seu comportamento inovador. Outro fator que contribuiu para a grande representatividade das informações foi o índice de resposta da pesquisa, ou seja, a resposta aos questionários foi da ordem de $84 \%$, sendo o índice de recusa de cerca de $16 \%$.

As informações da Paep apontaram que, no nível agregado, a taxa de inovação da indústria paulista, no período 1994-96, foi de $24,8 \%$, ou seja, cerca de um quarto de todas as empresas industriais paulistas introduziu alguma inovação de produto ou processo nesse período. A expressão econômica das empresas inovadoras paulistas é ainda maior: elas foram responsáveis por $68 \%$ do valor adicionado pela indústria de transformação no Estado de São Paulo (Gráfico 1). Com base nas informações captadas pela Paep, em 1996, havia 8.870 pessoas de nível superior alocadas em P\&D, na indústria de transformação paulista. Os setores que mais se destacavam eram a indústria automobilística, com 2.803 pessoas de nível superior alocadas em P\&D, seguida pela química (956) e outros equipamentos de transporte, que incluem a indústria aeronáutica (613), entre outras.

As informações sugeriam que o maior volume em $P \& D^{20}$ da indústria paulista (e brasileira) estava concentrado em segmentos industriais não intensivos em ciência, que apresentavam menores oportunidades tecnológicas. As indústrias produtoras de bens intermediários e algumas metal-mecânicas e elétricas convencionais compõem o grupo de indústrias brasileiras mais competitivas, e estão entre aquelas que desenvolveram uma considerável capacitação tecnológica.

\section{O Survey de Inovação na Paer}

A partir da avaliação da importância da Paep, a Fundação Seade foi convidada pelo Ministério da Educação-MEC, no âmbito do Programa de Expansão da Educação Profissional - Proep, a apresentar uma proposta para a realização de uma pesquisa similar, para ser aplicada em todos os Estados do Brasil, visando a reformulação do ensino profissionalizante do país. Aceita a proposta, a Fundação Seade iniciou, em 1998, o levantamento de campo das primeiras informações da Pesquisa da Atividade Econômica Regional - Paer, que incorpora, em grande medida, um subconjunto de variáveis (sobretudo qualitativas) da Paep, além de um detalhamento dos requisitos de contratação, requisitos para as rotinas de trabalho e instrumentos de seleção dos recursos humanos, bem como investigação sobre o relacionamento das empresas com as escolas técnicas e suas perspectivas de investimento e contratação de mão-de-obra. A Paer foi aplicada em todos os Estados do Brasil, levantando cerca de 19.038 unidades locais, distribuídas entre a indústria (10.583) e os serviços (8.455). A pedidos do MEC, a Fundação Seade enviou àquela instituição uma proposta para a realização da Paer/SP, cujo levantamento de campo foi realizado para o ano de 2001, ou seja, concomitante ao da Paep. Na Paer, para todos os Estados, a coleta de informações para a pesquisa se deu entre 1998 e 1999.

Na Paer, foi realizado um novo survey sobre inovação tecnológica. As informações sobre as atividades de inovação foram coletadas tendo como referência, em geral, o intervalo de 1995 a 1999. O universo de investigação desta pesquisa foi de 3.150 unidades locais da indústria com mais de 100 pessoas ocupadas, considerando a articulação deste segmento com o ensino técnico destas regiões. A representatividade destas informações, a exemplo da experiência da Paep, foi elevada, pois o índice de resposta foi da ordem de $95 \%$. Aproveitou-se o aprendizado metodológico adquirido através das atividades operacionais e de análise da Paep, no Estado de São Paulo, cujos principais avanços constituemse em dois aspectos centrais: atualização e inclusão de novas questões no instrumento de coleta, com base na versão do CIS-II, o questionário da pesquisa de inovação da Eurostat 


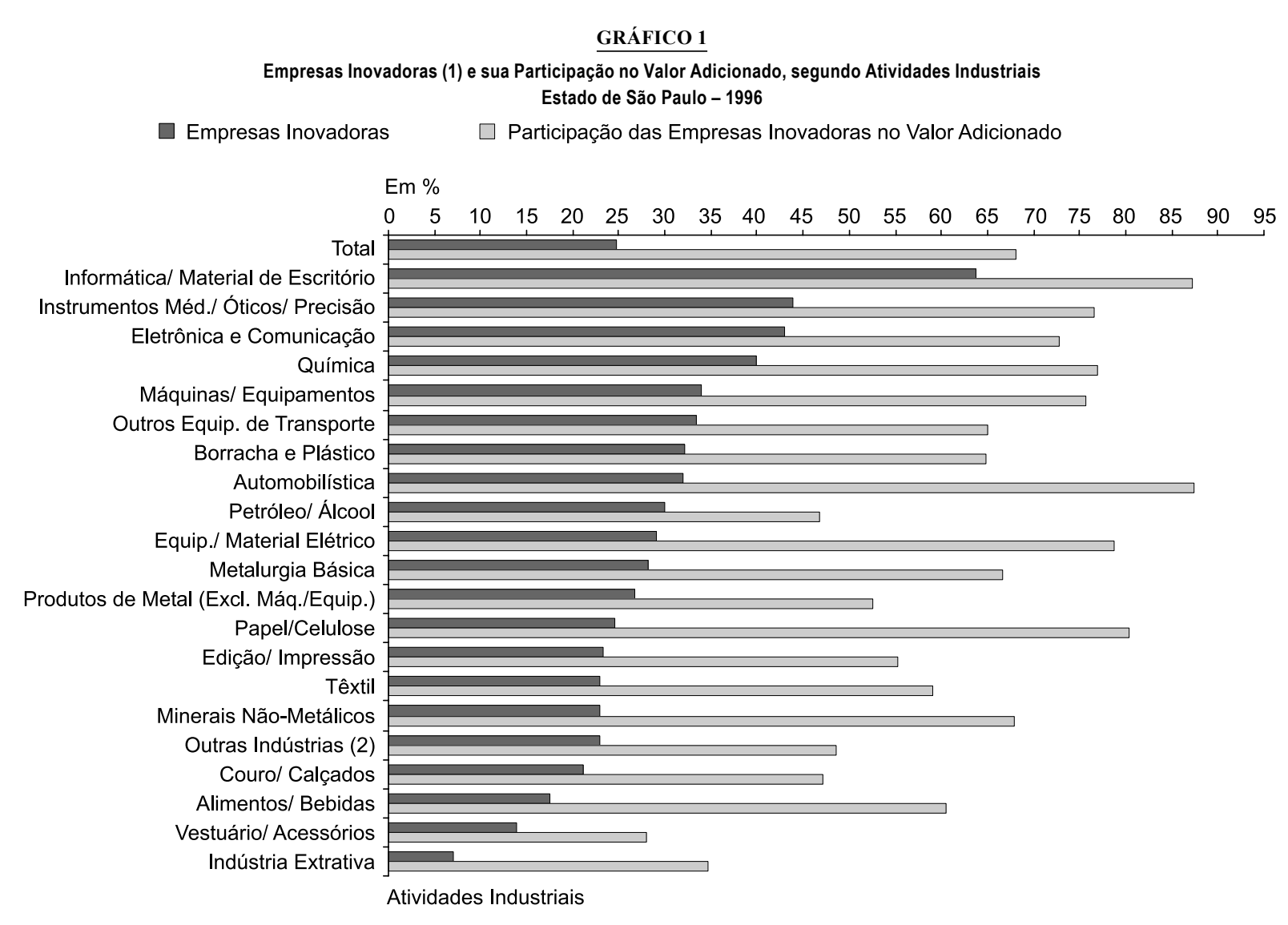

Fonte: Fundação Seade. Pesquisa da Atividade Econômica Paulista - Paep.

(1) Correspondem às empresas que desenvolveram ou introduziram alguma inovação de produto ou de processo (incremental ou significativa).

(2) Agregam as divisões: 16 - Fab. de Produtos do Fumo; 20 - Fabricação de Produtos de Madeira; e 36 - Fab. de Móveis e Indústrias Diversas.

Nota: Refere-se às empresas com sede no Estado de São Paulo.

(Statistical Office of the European Communities); e aprimoramento conceitual e metodológico das definições sobre inovação tecnológica, implicando maior rigor nos critérios de identificação e classificação das empresas inovadoras e, ao mesmo tempo, assegurando uma comparabilidade subnacional e internacional das informações obtidas. Baseandose nas novas questões do CIS-II, foram introduzidas as seguintes questões: solicitação à empresa da descrição da principal inovação de produto e/ou processo, que se mostrou apropriada para o trabalho de verificação da consistência da ocorrência de inovação e, portanto, para aperfeiçoar o rigor da pesquisa; identificação do principal agente do desenvolvimento do novo produto ou processo; indicação, pela empresa, se ela introduziu produtos que fossem tecnologicamente novos não apenas para ela, mas para o seu mercado. Tendo em vista a experiência da Paep, em que se verificou que o universo amostral das empresas inovadoras é composto majoritariamente por empresas de grande e médio portes, decidiu-se pela inclusão de um suplemento ao questionário da indústria da Paer, que foi aplicado nas empresas com 100 ou mais pessoas ocupadas e que possuíam sua sede localizada nos Estados investigados.

As performances das taxas de inovação das empresas industriais brasileiras com 100 ou mais empregados revelaram uma estrutura produtiva e um comportamento tecnológico regional heterogêneo. As pesquisas aplicadas entre 1994 e 1999 demonstram que o Estado de São Paulo apresentou uma taxa de inovação de cerca de 56\%, próxima à performance inovativa das empresas do Estado de Santa Catarina $(54,4 \%)$ e relativamente superior ao Amazonas (45,9\%), considerando particularmente a região de Manaus, e ao Rio Grande do Sul (46,7\%).

Quando comparada a participação relativa das empresas destes Estados em relação à sua importância nas 


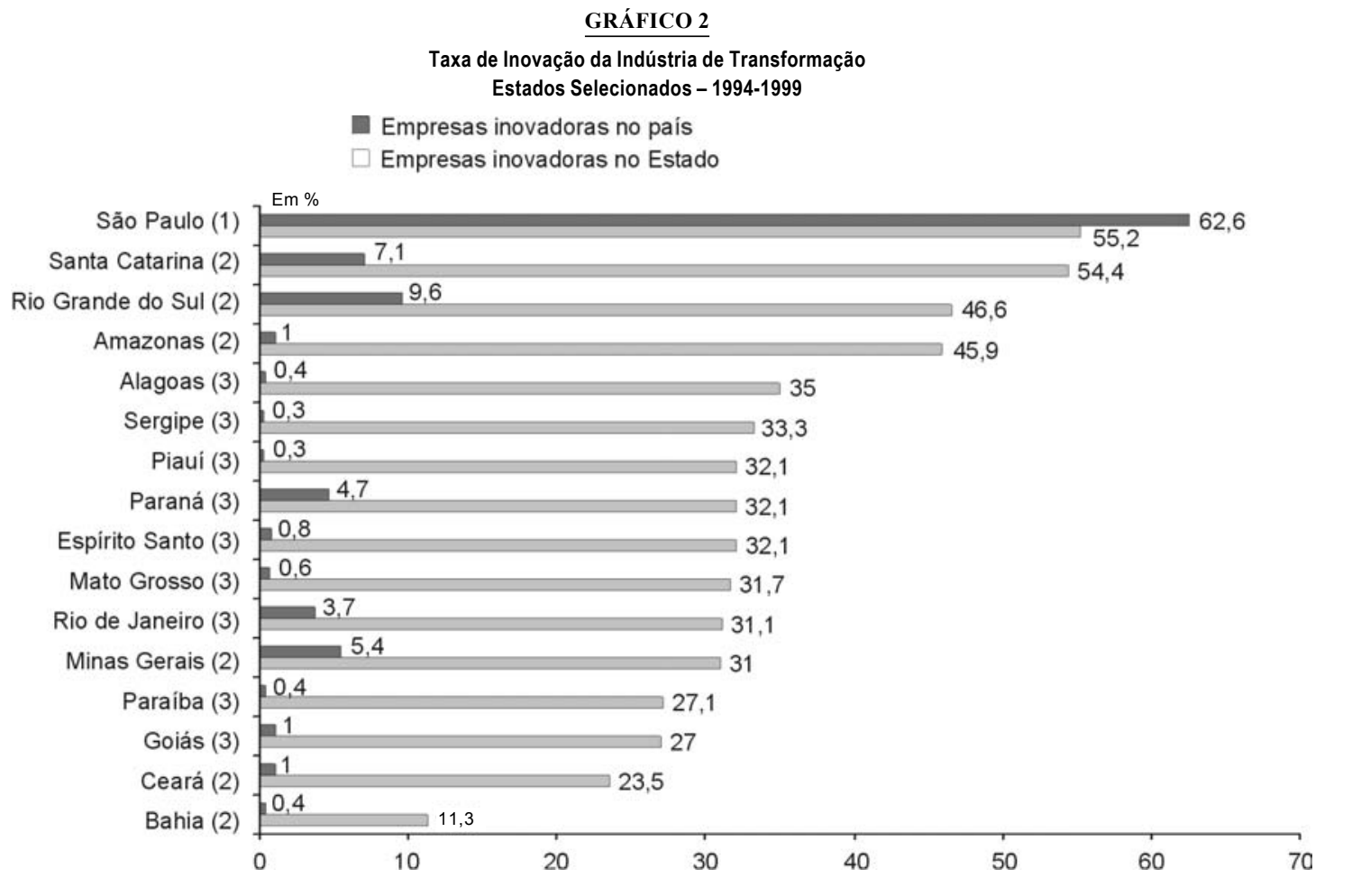

Fonte: Fundação Seade. Pesquisa da Atividade Econômica Paulista - Paep; Pesquisa da Atividade Econômica Regional - Paer.

(1) Refere-se ao periodo de 1994 a 1996.

(2) Refere-se ao período de 1994 a 1998

(3) Refere-se ao período de 1994 a 1999.

Nota: Participação percentual do número de empresas industriais com 100 e mais empregados com sede no Estado,

que realizaram inovação de produto e/ou processo sobre o total de empresas industriais com as mesmas características.

empresas inovadoras no país, a discrepância da representatividade regional é latente. O Estado de São Paulo respondia por $62,6 \%$ das empresas inovadoras no Brasil, enquanto Santa Catarina (7,1\%), Amazonas (1\%) e Rio Grande do Sul $(9,6 \%)$ apresentam participação significativamente menores.

As informações produzidas pela Paer revelaram que empresas inovadoras com participação de capital multinacional com mais de 100 pessoas ocupadas e que desenvolvem rotinas de P\&D são geograficamente concentradas no Estado de São Paulo. As informações evidenciaram a importante função que estas empresas desempenham no desenvolvimento tecnológico regional e nacional (Gráfico 2).

\section{O Survey de Inovação na Paep/2001: a inclusão do setor de serviços}

Com um importante apoio institucional e financeiro de agentes públicos, como Fapesp, MEC, Secretaria de
Ciência e Tecnologia e Secretaria de Economia e Planejamento do Estado de São Paulo, foi realizado um novo levantamento da Paep. Desta vez, a pesquisa foi realizada num período mais curto, captando informações sobre o ano-base de 2001 (para as informações quantitativas e financeiras) e o período entre 1999 e 2001 para as questões de inovação tecnológica, sendo o campo realizado entre agosto de 2002 e fevereiro de 2003. Para a execução da Paep/2001, foi utilizado o cadastro de empresas fornecido pelo IBGE - Cempre (jun./2001), do qual foram selecionados 1.006.037 registros de empresas de acordo com o âmbito Paep/2001. Consideraram-se todas as empresas com sede no Estado de São Paulo e empresas com sede fora do Estado com 30 ou mais pessoas ocupadas (PO) no Estado. Para os setores da indústria, instituição financeira e construção civil, foram consideradas as empresas com pelo menos cinco pessoas ocupadas. Já para os setores de comércio e serviços incluíram-se todas as empresas. 
Para a definição da amostra, as empresas da população de referência foram divididas em dois estratos: certo e aleatório. $\mathrm{O}$ estrato certo abrangeu as empresas com sede fora do Estado de São Paulo e que possuíam 30 ou mais pessoas ocupadas no Estado de São Paulo. O número de pessoas ocupadas foi contabilizado apenas nas unidades locais cujo setor era o mesmo que o da sede; foram consideradas as sedes no Estado de São Paulo dos setores da indústria, construção civil, comércio e instituição financeira com 30 ou mais pessoas ocupadas e dos serviços com 100 ou mais pessoas ocupadas. Para bancos, o recorte foi censitário, sendo entrevistados todos os bancos que operaram no Estado de São Paulo até 31 de dezembro de 2001.

Após o encerramento dos trabalhos de campo, a Paep/ 2001 obteve como resultado final cerca de $27.602 \mathrm{mil}$ questionários. Considerada a amostra inicial de 43.013 empresas, a quebra de cadastro foi da ordem de $12,7 \%$. O índice de recusa da coleta foi de $16,0 \%$, que pode ser considerado baixo no segmento de pesquisas econômicas. Os números apresentados demonstram a abrangência e a magnitude do banco de dados construído. No caso dos bancos, os resultados finais da pesquisa revelaram que os informantes representam cerca de $85 \%$ do ativo total do sistema bancário em 2001, podendo-se concluir que o resultado geral do campo foi satisfatório.

$\mathrm{Na}$ Paep/2001, além dos demais setores da pesquisa anterior, foram incluídas todas as atividades de serviços. $\mathrm{O}$ fato de a Fundação Seade ter desenvolvido uma metodologia de pesquisa sobre micro e pequenas empresas (Pecompe) sobre o setor de serviços para o Sebrae ${ }^{21}$ permitiu a apropriação de um grande conhecimento sobre o cadastro das informações das empresas, bem como definir com maior precisão uma classificação de atividades econômicas neste segmento. $\mathrm{O}$ levantamento do setor de serviços tornou-se um desafio metodológico devido a uma série de problemas de classificação, ao agregar sob uma mesma divisão de atividades diversas, que somente poderiam ser pesquisadas com instrumentos de coleta diferentes. Assim, se nos demais setores há uma comparação direta com a CNAE (em dois ou três dígitos), no caso dos serviços a classificação foi compatibilizada com outros levantamentos realizados pela Paer nos Estados do Brasil e com outros levantamentos do gênero (por exemplo, a Pesquisa Anual de Serviços, do IBGE). A classificação proposta pela Paep/2001 sugere uma divisão básica de 47 ramos, que poderão posteriormente ser desagregados: 21 industriais; quatro da construção civil; nove comerciais e 13 de serviços.
$\mathrm{Na}$ Paep/2001, para a formulação das questões de inovação, foi utilizado como referência o conjunto de questões organizadas no CIS-III, sendo que as questões relativas a automação e tecnologias de informação e comunicação foram elaboradas com base em outros surveys temáticos implementados pela OECD e Canadá. ${ }^{22} \mathrm{O}$ bloco de questões sobre inovação foi concebido através de intensa colaboração com os técnicos do IBGE, no sentido de harmonizar a metodologia e proporcionar uma complementariedade das informações geradas pela pesquisa industrial Pintec - Pesquisa de Inovação Tecnológica. ${ }^{23}$ As questões relativas à composição de custos financeiros da inovação, tais como dispêndios em P\&D interno e externo, treinamentos, aquisição de equipamentos para inovação, etc., não foram captadas pela Paep/2001 para que não se sobrecarregasse o questionário excessivamente, mas considerou-se a possibilidade de comparação com as informações captadas pela Pintec, que organizou um bloco específico e detalhado sobre estas questões.

De acordo com as recomendações do Manual de Oslo, da OECD, e já incorporando as discussões concluídas por essa organização no encontro de julho de 2001, este potencial analítico foi acrescido significativamente com a Paep/2001, mediante a aplicação do primeiro survey de inovação de serviços no Brasil. Ademais, na Paep/2001, os indicadores de inovação foram construídos a partir das possibilidades de cruzamento segundo os setores de atividade (indústria, construção civil, comércio, serviços, bancos e instituições financeiras), elevando ainda a possibilidade da regionalização das informações tecnológicas de inovação ${ }^{24}$ para as regiões administrativas do Estado de São Paulo. As empresas dos setores de indústria, comércio e serviços foram classificadas segundo a sede da empresa nas seguintes oito regiões que consistem em agregações de regiões administrativas do Estado de São Paulo: Região Metropolitana de São Paulo (exceto região do $\mathrm{ABC}$ ); $\mathrm{ABC}$; Litoral (Santos e Registro); São José dos Campos; Sorocaba; Campinas; Norte (Ribeirão Preto, São José do Rio Preto, Central, Barretos e Franca); Oeste (Bauru, Araçatuba, Presidente Prudente e Marília).

A Paep/2001 será divulgada no final de dezembro de 2003. Entretanto, alguns resultados preliminares já demonstram a alta concentração no padrão de localização dos laboratórios na Região Metropolitana de São Paulo, que abriga também uma robusta infra-estrutura de CT\&I (Mapa 1). 


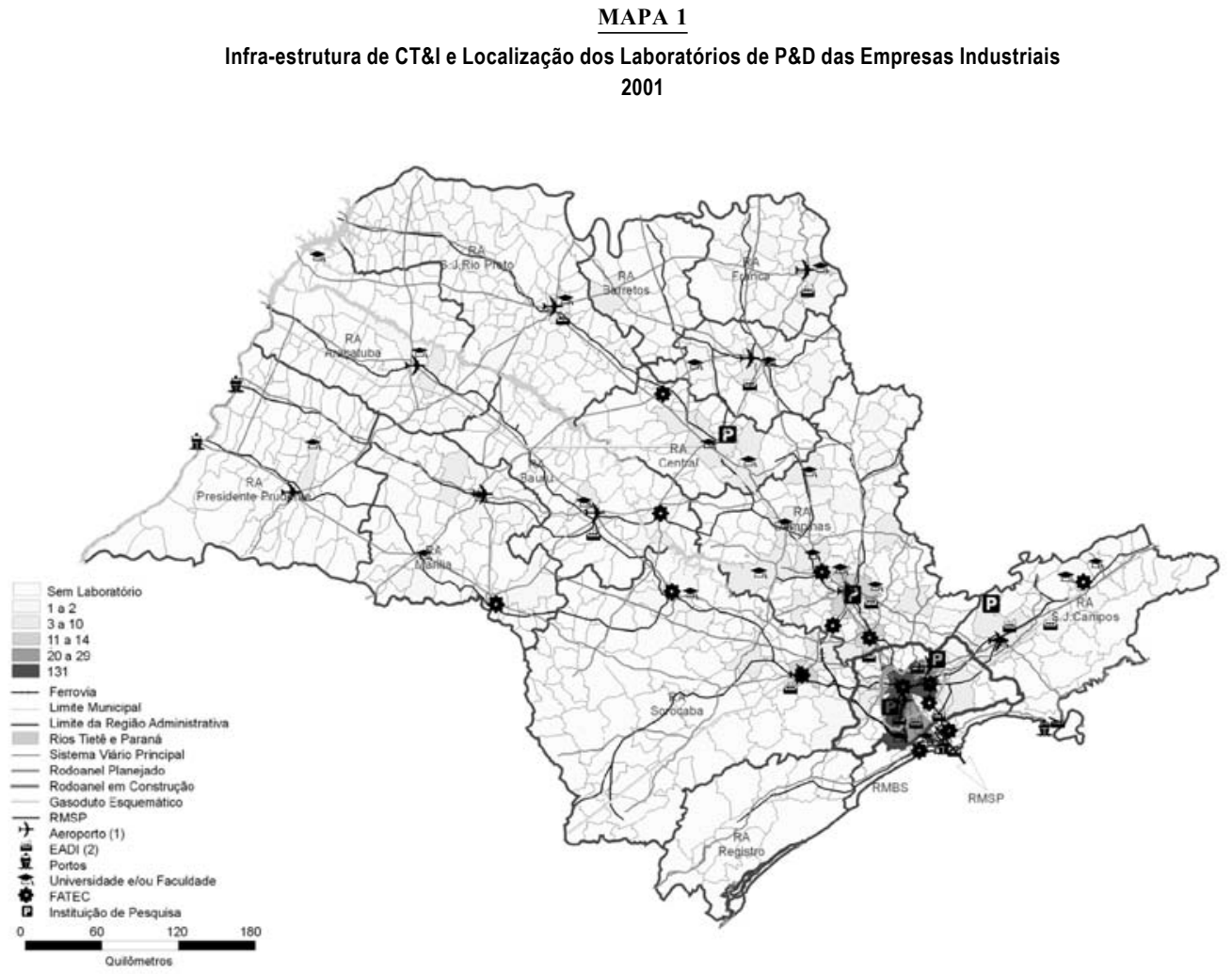

Fonte: Fundação Seade. Pesquisa da Atividade Econômica Paulista - Paep.

\section{CONCLUSÕES}

Neste artigo, espera-se ter demonstrado de forma sintética o grande desafio e o esforço coletivo institucional que consistiram a concepção, a gestão operacional e a disponibilização das informações de inovação nas Paeps e na Paer. Embora reconhecendo o longo caminho ainda a ser percorrido na produção de informações estatísticas, contabilizando os erros, acertos e as dificuldades reveladas pela pesquisa, parece que o balanço geral é positivo. A Paep e a Paer representaram um avanço no conhecimento institucional na produção de estatísticas econômicas e tecnológicas e na reflexão metodológica sobre as implicações e os resultados da aplicação dos conceitos de inovação recomendados pelo Manual de Oslo, possibilitando uma visão mais detalhada e integrada, assim como desenhar a cartografia do comportamento econômico e tecnológico empresarial nas diversas regiões do território nacional. Os resultados concluem que as informações da Paep e da Paer possibilitam a análise desagregada de um amplo conjunto de variáveis que permi- tem caracterizar os processos de difusão e inovação tecnológica nas empresas e nos territórios produtivos. Os desafios futuros na produção de estatísticas de inovação sinalizam para alguns pontos críticos: calibrar mais finamente a captação da inovação, qualificando melhor sua natureza, ou seja, o grau de novidade para o mercado; identificar o papel das multinacionais nos processos de aprendizagem e inovação local, mapeando os fluxos de origem da inovação (se partem de um centro de excelência nacional ou externo); compreender melhor a relação das empresas inovadoras com os centros de pesquisa e universidades locais, entre outros.

A experiência destas pesquisas demonstrou que é possível inovar na produção metodológica, desde que sejam considerados pelo menos três fatores estratégicos: o conhecimento da demanda e a interação com os usuários de informações; 0 estabelecimento de parâmetros de comparabilidade, sejam eles internacionais, nacionais ou subnacionais; e a própria continuidade destas novas séries históricas estatísticas. Uma das contribuições fundamentais da Paep é a disponibilização aos usuários de um amplo, sofisticado e diversificado 
banco de dados com informações convencionais e inéditas sobre a economia regional paulista contemporânea. Nesta ótica, da base de informações econômicas e cadastrais da Paep, poderão frutificar vários produtos analíticos ou projetos de pesquisas temáticas e acadêmicas. Com o novo projeto, será possível seqüenciar os gens que dão vida e vêm transformando a economia paulista, a partir do mapeamento e codificação das informações registradas entre as milhares de empresas que integram este complexo e diverso organismo. Através desta lente microscópica analítica, será possível mapear a evolução biológica das empresas, a arquitetura das cadeias produtivas, os padrões de inovação e aprendizado tecnológico, a interação das empresas com o sistema de CT\&I e sua distribuição geográfica no Estado de São Paulo. Este universo de questões poderá ser elucidado a partir dos resultados a serem apresentados pela Paep/2001.

\section{NOTAS}

1. A formulação de expressões como "economias baseadas em conhecimento", "sociedade da informação", "economia do aprendizado" e "capitalismo de alianças, relacional e coletivo" tenta retratar, grosso modo, a transição de um modelo linear de CT\&I para um modelo de ligações em cadeia (chain linked model), e posteriormente, alterandose para um padrão, no qual a idiossincrasia, diversidade e seletividade dos ambientes e das instituições, e os sistemas e redes (networks) de conhecimentos locais, regionais ou transterritoriais adquirem efeitos sinergéticos e sistêmicos mutuamente reforçantes ou excludentes em relação às oportunidades tecnológicas e à inserção dos espaços locais diante do processo de globalização econômica. Essa nova perspectiva teórica tenta traduzir o significado da produção, distribuição e do uso do conhecimento e da informação acelerados pelas novas tecnologias de informação e comunicação (TICs) como elementos nucleares para a mudança social, progresso tecnológico e o desenvolvimento econômico das nações avançadas (OECD, 1996; Johnson e Lundvall, 2000).

2. O manual Frascati foi revisado até 1993, quando foi lançada a quinta edição sob o título "The proposed Standard Practice for Surveys of Research and Experimental Development, Frascati Manial” 1993. As principais críticas aos indicadores de $\mathrm{P} \& \mathrm{D}$ podem ser sumarizadas nos seguintes tópicos: as rotinas de inovação são restritas às atividades de P\&D; avalia de forma inadequada a atividade inovativa nas pequenas e médias empresas, que não têm rotinas formalizadas, laboratórios ou unidades específicas para a condução destas atividades; não capta a eficiência dos esforços; o conceito de $\mathrm{P} \& \mathrm{D}$ não é preciso; subestima atividades inovativas relacionadas à mudança de processo (Archibugi; Sirilli, 2000).

3. Informações sobre a história e o acesso ao banco de indicadores organizados por esta instituição podem ser encontrados no site: <http:// www.nsf.gov/od/lpa/nsf50/history.htm>.

4. O Balanço de Pagamentos contempla o conjunto das transações econômicas de um país com os demais. Essas transações envolvem produtos (balança comercial), serviços (balança de serviços) e movimentos de capitais (investimentos diretos e de natureza financeira). $\mathrm{O}$ conceito de Balanço de Pagamentos Tecnológico inclui os fluxos de produtos e serviços com conteúdo tecnológico de um país.

5. Ver os comentários críticos sobre a base ISI no Relatório Fapesp de Indicadores de Ciência e Tecnologia em São Paulo, 1998 e Livro Verde, publicado pelo MCT, Brasília, julho, 2001. No Brasil, merece destaque a base de dados sobre publicações científicas internacionais do ISI, a base Scientific Electronic Library Online - Brazil - SciELO (que está sendo desenvolvida com o apoio da Fapesp), assim como a base de dados do Diretório dos Grupos de Pesquisa e do Sistema de Currículos Lattes do CNPq. Os indicadores de impacto da produção científica são constituídos pelas citações desses artigos, compiladas pela base de dados do ISI no Science Citation Index - SCI. As críticas quanto à representatividade latinoamericana na base do ISI referem-se a algumas áreas específicas, como ciências humanas e ciências agrárias, por exemplo, estão sub-representadas, comprometendo significativamente as análises sobre produção científica. Devem ser registradas as iniciativas de aperfeiçoamento dessas informações por meio de parcerias institucionais via Ricyt - Rede Iberoamericana de Indicadores de Ciência e Tecnologia e outras instituições que estão implementando iniciativas pioneiras para superar tais limitações. Um desses projetos denomina-se Latindex, organizado pela Universidade Nacional Autônoma do México - Unam.

6. No Brasil são duas as principais instituições que regulam as informações sobre as atividades de patentes e os fluxos tecnológicos. A primeira é o Inpi - Instituto Nacional de Propriedade Industrial, que se responsabiliza pelo controle dos contratos de transferência de tecnologia e registro de marcas, direitos autoriais e patentes, averbando as estimativas plurianuais de fluxos de remessas conforme expressas nos atos contratuais. A segunda é o Banco Central do Brasil, que atua no registro de todas as transações cambiais que compõem o Balanço de Pagamentos, contabilizando os ingressos e remessas associados aos atos de fechamento do câmbio dos contratos de transferência de tecnologia, além de cuidar de outras tarefas, como o registro do capital estrangeiro, que mantêm correlação com esses contratos.

7. As estatísticas de patentes possibilitam a construção de indicadores de avaliação da produção inventiva ao longo do tempo, de mudança tecnológica e de mensuração da competição tecnológica. As vantagens e limitações desses indicadores são apresentadas resumidamente a seguir: a) nem todo conhecimento economicamente útil é codificável, sobretudo o conhecimento tácito; b) nem toda inovação é patenteável, com referência às exigências legais mínimas; c) devido ao item anterior, há outros mecanismos de apropriação que podem ser considerados mais adequados em função da invenção; d) setores industriais variam consideravelmente suas propensões a patentear, sendo desaconselhável comparar essas taxas de efetividade ou eficiência entre indústrias; e) pode haver inconsistência de qualidade, isto é, as inovações patenteadas não possuem, necessariamente, o mesmo valor econômico.

8. Dois indicadores são utilizados para a classificação dos setores industriais por intensidade tecnológica: Intensidade direta - relação entre o grau dos dispêndios sobre o valor adicionado; e Intensidade indireta relação entre os gastos de P\&D sobre o valor adicionado, multiplicados pelos coeficientes técnicos dos setores obtidos a partir da matriz insumoproduto. Este procedimento se justifica pela incorporação de tecnologia, que, para um determinado setor, ocorre pela $P \& D$ incorporada na compra de bens e equipamentos e bens intermediários. Esta abordagem, entretanto, traz consigo inúmeras limitações, a saber: os recortes de intensidade tecnológica (alta, média-alta, média-baixa e baixa) são na maior parte das vezes arbitrários; as trajetórias de aprendizado e inovação setorial variam muito entre os países, setores e as firmas, não sendo captados por estes indicadores. OECD (1996) e Ferri e Martin (2001).

9. O Manual de Camberra é a principal publicação metodológica internacional que orienta as pesquisas sobre os recursos humanos e ocupações científicas de alta qualificação que contribuem para a produção da ciência, tecnologia e inovação nas economias baseadas em conhecimento ou em desenvolvimento. $\mathrm{O}$ objetivo deste manual é proporcionar o referencial metodológico e conceitual básico para o acompanhamento dos dados de estoque e fluxos de recursos humanos empregados e do perfil da estrutura ocupacional nestas economias.

10. Para os critérios de cálculo do TAI e ArCo, ver: Desai et al. (2003) e Archibugi e Coco (2003).

11. A primeira versão do Manual de Oslo foi publicada em 1992, seguida por uma segunda versão em 1996, após revisões e inclusão do 
setor de serviços. O Manual de Oslo traz definições e orientações metodológicas para a coleta e a análise de informações, recomendando seis áreas prioritárias para investigação: estratégia corporativa; papel da difusão; fontes de informação e obstáculos para inovação; insumos para inovação; o papel das políticas públicas na inovação industrial; e resultados e impactos da inovação (Ver: < http://www.oecd.org/pdf/ M00018000/M00018312.pdf>.

12. Na América Latina, no âmbito da Ricyt, tem sido desenvolvido um amplo debate metodológico sobre a necessidade de se rever as recomendações do Manual de Oslo para os critérios de inovação. Defende-se nesta vertente de autores latinos a necessidade de uma distinção entre as mudanças organizacionais na produção (uma vez que elas são elementos críticos para a inovação) e as não-inovações tecnológicas. Para uma discussão detalhada, ver Lugones e Peirano (2003).

13. Uma especificidade dos sistemas de aprendizados do continente que não foi explicitamente considerada nesta versão latino-americana do Manual de Oslo é a presença considerável de multinacionais estrangeiras como agentes importantes do processo de mudança tecnológica e de captacão de recursos para inovação nestes sistemas. Outra especificidade do Manual de Bogotá refere-se à inclusão da mudança organizacional no conceito de inovação tecnológica. Ver Costa (2003:78).

14. Uma das iniciativas mais significativas nesta área, entre outras, foi o estudo conduzido por Coutinho e Ferraz (1994).

15. Destaque-se o atual esforço do Diretório da Pesquisa Privada (DPP) na organização de um banco de dados sobre a natureza da mudança tecnológica e da organização P\&D no Brasil. O DPP foi concebido como um sistema de informação auxiliar na definição e implementação das políticas brasileiras de desenvolvimento de CT\&I. O objetivo é subsidiar as tomadas de decisões pelos organismos nacionais de fomento (Finep e MCT), propiciando uma alocação mais eficiente dos recursos e financiamento. Ver: <http://www.finep.gov.br/portaldpp/>.

16. O novo modelo de produção estatísticas proposto pelo IBGE adotou uma estratégia estruturada em alguns pontos críticos, a saber: elaboração e publicação de uma nova Classificação Nacional de Atividades Econômicas (CNAE); realização da Pesquisa do Censo Cadastro; reformulação das pesquisas anuais (PIA e PAC); e reação de pesquisas satélites, com substanciais ganhos de flexibilidade e agilidade operacionais.

17. Para maiores detalhes ver o texto de Proença Soares (1999).

18. Os exercícios de análise dos resultados desta pesquisa foram registrados em diversos trabalhos, entre eles ver: Quadros et al. (2001); Quadros, Bernardes e Franco (2002); entre outros. Para uma discussão crítica sobre a validade e os limites da análise de resultados de indicadores de inovação e capacitação tecnológica a partir de surveys de inovação, ver o trabalho de Ionara Costa (2003).

19. No que diz respeito aos indicadores de comércio eletrônico, foram analisados e adaptados os conceitos atribuídos pela OECD, Statistics Canada - E-commerce Definition, U.S. Bureau of the Census, European Information Technology Observatory - Eito. Ver: $<$ http://www.eito.com $>$.

20. A análise dos dados da Paep/96 permitiu estabelecer uma comparação entre o número de pessoas alocadas em atividades de $\mathrm{P} \& \mathrm{D}$ na indústria paulista e em outros países. Assim, a despeito das diferenças temporais e conceituais envolvidas na obtenção deste tipo de indicador pela Paep e por outras estatísticas internacionais que adotaram a mesma metodologia, verifica-se o hiato entre o volume de esforço em $\mathrm{P} \& \mathrm{D}$ produzido por países industrializados, como Estados Unidos, Japão, Alemanha e França, e por países em desenvolvimento, como Brasil, México, Espanha e Hungria. Ver: Quadros, Furtado, Bernardes e Franco (1999).

21. Para maiores informações sobre esta pesquisa consultar o site: $<$ http://www.sebraesp.com.br/>.

22. Ver o estudo metodológico sobre medidas e conceitos sobre pesquisas internacionais sobre inovação tecnológico elaborado por Giorgio Sirilli (1998).

23. A referência conceitual e metodológica da Pintec segue o Oslo manual: proposed guidelines for collections and interpreting technological innovation data 1997. A pesquisa se inspirou na experiência do modelo harmonizado proposto pelo Eurostat, a terceira versão da Community Innovation Survey. Seguindo tais referências, as informações da Pintec concentram-se na inovação tecnológica de produtos e processos, sendo adotada a abordagem do "sujeito", ou seja, as informações obtidas são relativas ao comportamento, às atividades empreendidas aos fatores que influenciam a empresa. A maioria das variáveis qualitativas refere-se a um período de três anos consecutivos, de 1998 a 2000, e as informações quantitativas são para o ano de 2000. A pesquisa abrangeu todas as empresas industriais do território nacional. As informações da Pintec estão disponibilizadas no site do IBGE: <http://www.ibge.gov.br/>.

24. No Brasil, avanços recentes no sentido de regionalizar as informações foram empreendidos pela RedeSist (Rede de Pesquisa em Sistemas Produtivos e Inovativos Locais), uma rede de pesquisa interdisciplinar, formalizada desde 1997, sediada no Instituto de Economia da Universidade Federal do Rio de Janeiro. A RedeSist produziu e disponibilizou em seu site um Banco de Indicadores Georreferenciados - BIG organizado pela própria RedeSist sistematizando bases de dados de diversas fontes e indicadores de elaboração própria, em especial, referentes aos municípios brasileiros e aos arranjos e sistemas produtivos pesquisados pela RedeSist. Ver: $<\mathrm{http}: / / \mathrm{www}$.ie.ufrj.br/redesist>.

\section{REFERÊNCIAS BIBLIOGRÁFICAS}

ARCHIBUGI, D.; COCO, A. A new indicator of technological capabilities for developed and developing countries ( $\mathrm{ArCo})$. The First Globelics Conference Innovation Systems and Development Strategies for the Third Millennium. Rio de Janeiro, November 262003.

ARCHIBUGI, D.; SIRILLI, G. The direct measurement of technological innovation in business. Roma: National Research Council, 2000 (paper).

CASSIOLATO, J.E.; LASTRES, H. Inovação, globalização e as novas políticas de desenvolvimento industrial e tecnológico. Cluster e sistemas locais de inovação: estudos de casos e avaliação da região de Campinas. Campinas, Unicamp Instituto de Economia, set. 1999.

COSTA, I. Empresas multinacionais e capacitação tecnológica na indústria brasileira. 2003. Tese (Doutorado em Política Científica e Tecnológica) - Universidade Estadual de Campinas/Instituto de Geociências, Campinas, 2003.

COUTINHO, L.; FERRAZ, J.C. (Coord.). Estudo da competitividade da indústria brasileira. São Paulo: Papyrus, 1994.

DESAI, M.; FUKUDA-PARR, S.; JOHANSSON, C.; SAGATI, F. Measuring technology achievement of nations and the capacity to participate in the network age. PNUD, 2001. Disponível em: $<$ http:/ /www.statistics.gov.uk/IAOSlondon2002/contributed_papers/ IP Desai.as>. Acesso em: 24 set. 2003.

DOSI, G. The contribution of economic theory to the understanding of a knowledge-based economy. In: OECD. The knowledge-based economy. Paris, 1998

FERRI, J.L.C.; MARTIN, C.A. Indicadores de alta tecnologia. Madri: Instituto Nacional de Estatística, 2001 (Documentos de Trabajo, 5/10).

FIGUEIREDO, P.N. Technological learning and competitive performance. Cheltenham e Orthhampton: Edward Elgar, 2001.

GUELLEC, D.; PATTINSON, B. Innovation surveys: a few lessons from OECD countries experience, In: $4^{\text {th }}$ INTERNATIONAL CONFERENCE ON TECHNOLOGY POLICY AND INNOVATION. Curitiba: OECD, Secretariat, August 2002. (Preliminary draft).

JARAMILLO, H.; LUGONES, G.; SALAZAR, M. Manual de Bogotá: normalización de indicadores de innovación tecnológica en Amé- 
rica Latina y el Caribe. Proyecto Financiado por la Organización de Estados Americanos OEA. Bogotá, Colombia, 2000.

JOHNSON, B.; LUNDVALL, B.A. Promoting innovation systems as a response to the globalising learning economy. In: INTERNATIONAL SEMINAR ON LOCAL PRODUCTIVE CLUSTERS AND INNOVATION SYSTEMS AND NEW INDUSTRIAL AND TECHNOLOGICAL POLICIES. Rio de Janeiro, Universidade do Rio de Janeiro, set. 2000.

KATZ, J. (Ed.). Technology generation in latin-american manufacturing industries. Basingstoke: MacMillam, 1987.

KLINE, S.J.; ROSEMBERG, N. An overview of innovation. In: LANDAU, R.; OECD. Transitions to learning economies and societies. Paris, 1996a.

. The knowledge-based economy. Paris, 1996b.

An overview of innovation. In: LANDAU, R.; ROSEMBERG, N. (Ed.). The positive sum strategy. Harnessing technology for economic growth. Washington: National Academy Press, 1986.

LUGONES, G.; PEIRANO, F. The innovation surveys in Latin America: results and methodological novelties. The First Globelics Conference Innovation Systems and Development Strategies for the Third Millennium. Rio de Janeiro, November 2-6 2003.

LUNDVALL, B.A. National systems of innovation: towards a theory of innovation and interactive learning. London: Printer, 1992.

OECD. Science, technology and Industry Outlook. Science and Innovation, 2000.

Revision of the high-technology and product classification. Paris, v.97, n.216, 1996. 1995a.

. Main science and technology indicators 1995 (1). Paris,

. Research and development expenditure in industry: 19731992. Paris, 1995b.

. Manual Frascati, 1993. Paris, OECD, 1994.

Oslo Manual. Paris, OECD, 1993.
PROENÇA SOARES, L.H. Sobre os modos de fazer: novas institucionalidades para as pesquisas econômicas em São Paulo. São Paulo em Perspectiva, São Paulo, Fundação Seade, v.13, n.12, jan./jun. 1999.

QUADROS, R.; FURTADO, A.; BERNARDES, R.; FRANCO, E. Padrões de inovação tecnológica na indústria paulista: semelhanças e diferenças em relação aos países industrializados. São Paulo em Perspectiva, São Paulo, Fundação Seade, v.13, n.1-2, jan./jun. 1999.

QUADROS, R.; FURTADO, A.; BRISOLLA, S.; BERNARDES, R. Força e fragilidade do sistema de inovação paulista. São Paulo em Perspectiva, São Paulo, Fundação Seade, v.14, n.3, jul./set. 2001.

QUADROS, R.; BERNARDES, R.; FRANCO, E.C. Inovação tecnológica na indústria - Resultados da Paep/Seade. In: VIOTTI, E.B. e MACEDO, M. de M. (Coord.). Projeto indicadores sobre ciência, tecnologia e inovação no Brasil. Campinas, Ed. Unicamp, 2003.

SIRILLI, G. Conceptualising and measuring technological innovation. In: II CONFERENCE ON TECHNOLOGICAL POLICY INNOVATION, Aug. 1998.

SMITH, K. Innovation indicators and the knowledge economy: concepts, results and policy challenges. Oslo: STEP Group, nov. 2000. Mimeografado.

STUZ, J. La innovación realmente existente en América Latina: medidas y lecturas (Universidad de la Republica). Apresentada para o Projeto Globalização e Inovação Localizada: Experiências de Sistemas Locais no Âmbito do Mercosul e Proposições de Políticas de C\&T. Rio de Janeiro, IE/UFRJ, 1999. (Nota Técnica n. 33/99).

Roberto Bernardes: Professor colaborador do Departamento de Politica Científica e Tecnológica/Instituto de Geociências/Unicamp, Analista da Fundação Seade (rcbernar@seade.gov.br). 